\title{
O uso da programação para atração de mulheres à computação: relatos de experiência
}

\author{
Juliana M. Oliveira dos Santos, Karen A. dos S. Pereira, Débora Abdalla Santos \\ Departamento de Ciência da Computação - Universidade Federal da Bahia (UFBA) \\ Grupo de Pesquisa e Extensão em Informática, Educação e Sociedade - Onda Digital \\ Av. Adhemar de Barros, s/n - Ondina - CEP 40.170-110 - Salvador - BA - Brasil \\ juliana.maria@ufba.br, karen.asnt@gmail.com, abdalla@ufba.br
}

\begin{abstract}
This article presents an experience report of the project "Meninas Digitais - Regional Bahia" (Digital Girls - Chapter Bahia) with the objective of arousing interest of women in areas of computer science through the teaching of computer programming. Throughout the article, students' progress monitoring strategies, teaching methodologies and results of the classes of Computer programming initiation course and JavaScript Programming with Games course are discussed.
\end{abstract}

\begin{abstract}
Resumo. Este artigo apresenta um relato das experiências do Projeto Meninas Digitais - Regional Bahia com o objetivo de despertar o interesse de mulheres para a área de computação por meio do ensino de programação de computadores. Ao longo do artigo, as estratégias de acompanhamento do progresso das alunas, as metodologias de ensino e os resultados das turmas do Curso de Iniciação à Programação de Computadores e da turma do Curso de Programação JavaScript com Jogos são discutidos.
\end{abstract}

\section{Introdução}

A Computação é uma área do conhecimento presente em praticamente todas as atividades humanas e a compreensão dos seus princípios e práticas contribui para formação de cidadãos mais críticos, autônomos, colaborativos e criativos. Diversos trabalhos vêm sendo desenvolvidos na área de ensino de computação, seja na Educação Básica ou Ensino Superior, com especial destaque para a área de programação e pensamento/raciocíonio computacional, como evidenciado nos trabalhos de [Bordini et al, 2016] e [Aureliano e Tedesco, 2012].

A programação é uma área promissora, rica em possibilidades de atuação e crescimento pessoal e profissional e que possibilita contribuir para a melhoria das necessidades atuais e futuras da sociedade. O uso da programação de computadores é também uma prática eficaz para o desenvolvimento de competências, como resolução de problemas, criatividade e colaboração [Neves, 2017]. Na opinião do co-fundador da ONG Code.org, o iraniano Ali Partovi, "saber programar vai se transformar no novo ler e escrever. Quem não souber código terá mais dificuldade para entender o mundo".

Dados do Censo Demográfico de 2010 mostram que dos quase 520 mil profissionais de atividades dos serviços de tecnologia da informação, apenas $25 \%$ são mulheres. Somado a isso, dados de survey realizado no Stack Overflow, website especializado em perguntas sobre programação, com mais de 100.000 desenvolvedores de todo mundo, mostra que dentre 
aqueles que responderam à questão relacionada a gênero, mais de $90 \%$ da amostra é representada por homens, cerca de $7 \%$ mulheres e $1 \%$ não-binário.

Este trabalho relata atividades de extensão desenvolvidas com o objetivo de despertar o interesse de mulheres para a área de computação por meio de cursos de programação com turmas exclusivas para mulheres. As próximas seções deste trabalho estão organizadas da seguinte maneira: a Seção 2 apresenta a organização dos cursos, a Seção 3 descreve as atividades desenvolvidas. A discussão e avaliação dos resultados é apresentada na Seção 4, e por fim, as considerações finais são tratadas na Seção 5.

\section{Cursos de Extensão na Área de Programação}

Dados da Pesquisa Nacional de Amostra por Domicílios (PNAD) mostram que 79\% das mulheres que entram nas faculdades da área de Tecnologia da Informação (TI) abandonam o curso no primeiro ano, e este exôdo é, por vezes, incentivado pelo próprio ambiente acadêmico considerado hostil e machista. As turmas exclusivas para mulheres criam um ambiente mais seguro, onde as mulheres se sentem mais confortáveis para perguntar e não se sentir julgada por errar, além de desenvolver a autoconfiança.

O Projeto Onda Solidária de Inclusão Digital (POSID), integrante do programa permanente de extensão da Universidade Federal da Bahia (UFBA), o Onda Digital, realiza, desde 2013, o Curso de Iniciação à Programação de Computadores (CIProg). Com a implantação do Projeto Meninas Digitais - Regional Bahia, em 2016, o curso passou a ser ministrado também para turmas exclusivas de mulheres, com o apoio de estudantes do componente curricular, modalidade disciplina e de caráter extensionista, denominado Ação Curricular em Comunidade e em Sociedade (ACCS): Onda Solidária de Inclusão Digital Tecnologia a Serviço de Cidadania. O curso é ofertado para mulheres (cis e trans) com conhecimentos em informática básica que, preferencialmente, não tenham contato com programação de computadores.

O CIProg tem por objetivo apresentar noções iniciais de programação e desenvolver habilidades para resolução de problemas por meio de algoritmos e do raciocínio computacional. Adotando o paradigma imperativo, a ementa aborda os seguintes conteúdos: raciocínio lógico; algoritmos; declaração de variáveis e constantes; tipos de variáveis; instruções de entrada e saída; operadores aritméticos e lógicos; estruturas de controle; estruturas de repetição e vetores [Ferreira et al, 2016].

Por demanda, uma experiência piloto do Curso de Programação JavaScript com Jogos (CPJJ) foi realizada para atender o interesse de alunas que queriam dar continuidade aos estudos. O CPJJ teve por objetivo aprimorar os conhecimentos em programação e introduzir o paradigma de orientação a objetos às participantes, com foco no desenvolvimento de jogos utilizando softwares livres. A ementa contempla: história dos jogos e gameplays, introdução ao JavaScript, tipos de dados, estruturas condicionais, estruturas de repetição, objetos e métodos, vetores, funções, aplicativos com HTML e bibliotecas JavaScript.

A seleção para os cursos é composta de duas etapas: inscrição via formulário eletrônico e entrevista. A metodologia de ensino e os recursos voltados ao ensino de programação sofreram alterações a cada edição do curso, pois as atividades são avaliadas tanto pela equipe de execução quanto pelos participantes, provocando mudanças que trazem benefícios para a ação, pautando-se nos princípios da pesquisa-ação [Thiollent, 1985]. 


\section{Atividades Desenvolvidas}

Durante os últimos quatro semestres letivos da UFBA foram ofertadas quatro turmas do Curso de Iniciação à Programação de Computadores (CIProg) e uma turma do Curso de Programação JavaScript com Jogos (CPJJ). Apenas para a primeira turma dos cursos foi estabelecida a idade máxima de 40 anos para as participantes. Nas demais turmas, era suficiente ter idade a partir de 15 anos, sem limitação de idade.

O Quadro 1 sintetiza as informações referentes ao perfil das turmas. De forma resumida, apresentamos no Quadro 2, a distribuição de instrutores e monitores por gênero, os recursos e ferramentas utilizadas para linguagem de programação, os recursos utilizados para comunicação e as linguagens de programação utiizadas em casa curso. A T03 - CIProg e a T01 - CPJJ foram ofertadas no mesmo período.

Quadro 1. Quadro-resumo do perfil das turmas

\begin{tabular}{|c|c|c|c|c|c|}
\hline Variáveis & T01 - CIProg & T02 - CIProg & T03 - CIProg & T04 - CIProg & T01 -CРJJ \\
\hline Vagas ofertadas & 30 & 25 & 40 & 25 & 15 \\
\hline Dias para inscrição & 5 & 14 & 9 & 7 & 9 \\
\hline Carga horária total & $24 \mathrm{~h}$ & $36 \mathrm{~h}$ & $36 \mathrm{~h}$ & $32 \mathrm{~h}$ & $36 \mathrm{~h}$ \\
\hline Período do curso & Ago a Out/2016 & Jan a Mar/2017 & Jun a Ago/2017 & Nov a Jan/2018 & Jun a Ago/2017 \\
\hline Periodicidade & $1 \mathrm{x}$ por semana & $2 \mathrm{x}$ por semana & 1x por semana & 1x por semana & 1x por semana \\
\hline Qdtde de encontros & 12 & 18 & 10 & 9 & 10 \\
\hline $\begin{array}{l}\text { No de pré-inscritas }^{\text {(média de idade) }} \\
\text { (mén }\end{array}$ & $\begin{array}{c}83 \\
(26,06 \text { anos })\end{array}$ & $\begin{array}{c}72 \\
(24,14 \text { anos })\end{array}$ & $\begin{array}{c}61 \\
(24,89 \text { anos })\end{array}$ & $\begin{array}{c}29 \\
(23,28 \text { anos })\end{array}$ & $\begin{array}{c}19 \\
(25,68 \text { anos })\end{array}$ \\
\hline $\begin{array}{l}\mathrm{N}^{\circ} \text { de matriculadas } \\
\text { (média de idade) }\end{array}$ & $\begin{array}{c}30 \\
(24 \text { anos })\end{array}$ & $\begin{array}{c}25 \\
(23,52 \text { anos })\end{array}$ & $\begin{array}{c}27 \\
(24,67 \text { anos })\end{array}$ & $\begin{array}{c}15 \\
(24,27 \text { anos })\end{array}$ & $\begin{array}{c}11 \\
(27,91 \text { anos })\end{array}$ \\
\hline $\begin{array}{l}\mathrm{N}^{\mathrm{o}} \text { de concluintes } \\
\text { (média de idade) }\end{array}$ & $\begin{array}{c}13 \\
(22,46 \text { anos }) \\
\end{array}$ & $\begin{array}{c}10 \\
(18,5 \text { anos }) \\
\end{array}$ & $\begin{array}{c}17 \\
(26,71 \text { anos) } \\
\end{array}$ & $\begin{array}{c}8 \\
(23,25 \text { anos }) \\
\end{array}$ & $\begin{array}{c}7 \\
\text { (27 anos) } \\
\end{array}$ \\
\hline Taxa de aprovação & $43 \%$ & $40 \%$ & $63 \%$ & $53 \%$ & $64 \%$ \\
\hline Taxa de desistência $1^{1}$ & $57 \%$ & $60 \%$ & $37 \%$ & $47 \%$ & $36 \%$ \\
\hline
\end{tabular}

Quadro 2. Quadro-resumo dos recursos utilizados

\begin{tabular}{|c|c|c|c|c|}
\hline Turmas & $\begin{array}{c}\text { Instrutores e } \\
\text { Monitores }\end{array}$ & Recursos Utilizados & $\begin{array}{l}\text { Recursos para } \\
\text { Comunicação }\end{array}$ & Linguagens \\
\hline $\begin{array}{l}\text { CIProg }- \text { T01 } \\
\quad(2016.1)\end{array}$ & 5 homens & $\begin{array}{c}\text { Code.org, computação } \\
\text { desplugada, VisuAlg IDE }\end{array}$ & $\begin{array}{c}\text { Moodle, Facebook e } \\
\text { WhatsApp }\end{array}$ & Scratch e Portugol \\
\hline $\begin{array}{l}\text { CIProg }- \text { T02 } \\
\quad(2016.2)\end{array}$ & $\begin{array}{l}3 \text { mulheres e } \\
2 \text { homens }\end{array}$ & $\begin{array}{c}\text { Repl.it, Geany IDE, } \\
\text { gamificação, DoJo, filmes }\end{array}$ & Moodle e Telegram & Portugol e C \\
\hline $\begin{array}{l}\text { CIProg }- \text { T03 } \\
\quad(2017.1)\end{array}$ & $\begin{array}{l}2 \text { mulheres e } \\
2 \text { homens }\end{array}$ & $\begin{array}{c}\text { Repl.it, Geany IDE, } \\
\text { gamificação, participação em } \\
\text { eventos }\end{array}$ & Moodle e Telegram & $\mathrm{C}$ \\
\hline $\begin{array}{l}\text { CIProg - T04 } \\
(2017.2)\end{array}$ & 3 mulheres & Repl.it, gamificação & Moodle e Telegram & $\mathrm{C}$ \\
\hline $\begin{array}{l}\text { CPJJ - T01 } \\
(2017.1)\end{array}$ & $\begin{array}{l}4 \text { mulheres e } \\
1 \text { homem }\end{array}$ & Brackets, Repl.it, gameonato & Moodle e Telegram & JavaScript \\
\hline
\end{tabular}

1 As desistências referem-se à alunas que compareceram em nenhuma ou no máximo duas aulas e/ou que precisaram desistir por falta de tempo. 


\section{Discussão e Avaliação dos Resultados}

Nos nossos cursos a avaliação da aprendizagem ocorre de maneira processual, por meio do acompanhamento das alunas nas aulas presenciais e no Ambiente Virtual de Aprendizagem (AVA) Moodle UFBA, buscando identificar dificuldades de aprendizagem e corrigi-las antes de avançar nos conteúdos. Com a prática adotamos o hábito de reservar um momento nas aulas para corrigir as atividades do Moodle, de maneira colaborativa com cada aluna descrevendo os passos que pensou para solucionar o problema proposto. Já está consolidado o uso do software livre Moodle nos cursos com gamificação alusiva à participação das mulheres na história da computação. O software livre Telegram é utilizado para comunicação da turma e espaço de prática com o desenvolvimento de bots, stickers e jogos no aplicativo.

Para aprovação no curso é necessário ter frequência mínima de $75 \%$ nos encontros presenciais e aproveitamento avaliado como satisfatório pelos instrutores. O aproveitamento é verificado pela realização das atividades presenciais e virtuais, participação e engajamento, além de realização de um projeto final com o objetivo de estimular a pesquisa, desenvolver os conhecimentos aprendidos ao longo do curso e o convívio em equipe. Nos projetos finais sugere-se a criação de soluções/ideias com foco nas mulheres, estimulando a criatividade e reflexão quanto ao consumo (à produção) de aplicações voltadas para mulheres.

Durante os cursos foram propostas atividades que promoviam maior interação como o método de aprendizagem Coding DoJo que possibilitou a participação conjunta na construção de códigos. Em um dos semestres tivemos a coincidência do lançamento do filme "Estrelas Além do Tempo", assim foi organizada uma ida conjunta com as alunas para o cinema e posterior discussão do filme, colaborando para fundamentar o debate sobre a presença de mulheres nas ciências exatas. Já foi organizada também a participação das alunas na área aberta do evento de tecnologia Campus Party Salvador 2017.

O CPJJ foi uma experiência piloto com foco em atrair mulheres no desenvolvimento de jogos, área que apesar de figurar mulheres como maioria de usuárias, configura-se em um espaço de preconceito e assédio, como aponta o trabalho de [Caetano, 2016]. No curso foram desenvolvidos diversos jogos utilizando a plataforma Brackets e a biblioteca Phaser. O maior desafio foi encontrar softwares livres específicos para o desenvolvimento de jogos.

$\mathrm{Na}$ primeira turma do curso de programação onde toda a equipe de instrutores e monitores era composta por homens, foram feitas algumas críticas e questionamentos por parte das alunas pela ausência de mulheres na equipe. Observamos que nas turmas onde a maioria da equipe de instrutores era composta por mulheres, houve menor desistência do corpo discente. O depoimento a seguir ilustra a importância de ofertar turmas para mulheres: "Preciso aprender a programar pro meu curso, mas não consegui aprender nada (mesmo) durante as aulas. Sei muito pouco sobre programas de computador, só sei mesmo o básico. Acredito que seria um diferencial para mim, principalmente por ser um curso somente para mulheres. Eu não me sinto confortável aprendendo na sala de aula (e também não me sinto confortável pedindo ajuda aos meus amigos para aprender a programar, pois como sei muito pouco de computador, fico com vergonha)" (estudante de Engenharia Química).

\section{Considerações Finais e Trabalhos Futuros}

Por meio dessa ação queremos mostrar a Computação como um espaço possível para todos, independente de gênero, idade, sexualidade, raça, etnia ou qualquer outra classificação. A 
computação para todos e todas deve ser problematizada e discutida para vencermos os estereótipos culturais, os preconceitos e a desigualde institucionalizada. Os resultados palpáveis e que nos faz acreditar que está ação mostra-se efetiva são depoimentos de alunas participantes do projeto: “(...) eu já tinha contato com programação, pois sou estudante do curso de Análise e Desenvolvimento de Sistemas, mas estava desmotivada e pensando em desistir. (...) olhar para os lados e não ver alguém para me inspirar, sabe? (...) a medida que o tempo foi passando começou a me incomodar, era como se meu gênero justificasse as minhas notas. (...) Chegava a passar mal só de pensar em fazer uma prova ou qualquer atividade que fosse. (...) foi por meio do Onda Digital que eu decidi continuar. E de verdade, foram a luz no fim do túnel. (...) eu não havia tido contato com o Linux, e hoje eu sou encantada e utilizo muito" (Depoimento de aluna da T02 - CIProg).

Nas próximas edições do curso pretendemos realizar melhorias na gamificação do AVA e disseminar tutoriais de configuraçãopara interessados. Além disso, pretendemos reestruturar o curso para atender a demanda de novas modalidades e realizar o acompanhamento de alunas egressas, convidando-as para atuar como monitoras em novas turmas, para mostrá-las que além de aprender também são capazes de apoiar outras mulheres que no momento desejem conhecer e/ou permanecer na área de Computação.

\section{Referências}

Aureliano, V. C. O.; Tedesco, P. C. A. R. Ensino-aprendizagem de Programação para Iniciantes: uma Revisão Sistemática da Literatura focada no SBIE e WIE. In: XXIII Simpósio Brasileiro de Informática na Educação - SBIE, 2012.

Bordini, A. et al. Computação na Educação Básica no Brasil: o Estado da Arte. Revista de Informática Teórica e Aplicada, v. 23, n. 2, p. 210-238, 2016.

Caetano, M. A. Joguem como mulheres ou como garotas! In: Anais do XV Simpósio Brasileiro de Jogos e Entretenimento Digital, p. 905-913, 2016.

Ferreira, A. C. et al. Hello World: relato de experiência de um curso de iniciação à programação. In: Anais dos Workshops do Congresso Brasileiro de Informática na Educação, v. 5, n. 1, p. 1306, 2016.

IBGE. Censo Demográfico 2010: trabalho e rendimento. Disponível em: https://biblioteca.ibge.gov.br/index.php/biblioteca-catalogo?view=detalhes\&id=71075. Acesso em 06 abr 2018.

Neves, M. Aprender a programar, programar para aprender. ISTOÉ Inependente. Disponível em https://istoe.com.br/aprender-programar-programar-para-aprender/. Acesso em: 06 abr 2018.

PNAD. Síntese de Indicadores 2009. Disponível em: https://biblioteca.ibge.gov.br/visualizacao/livros/liv45767.pdf. Acesso em: 06 abr 2018.

Stack OverFlow. Developer Survey Results 2018. Disponível em: https://insights.stackoverflow.com/survey/2018/? utm_source=Iterable\&utm_medium=email\&utm_campaign=dev-survey-2018-promotion. Acesso em 06 abr 2018.

Thiollent, M. (1985) Metodologia da Pesquisa - Ação. São Paulo: Cortez 